\title{
TRABALHO E RESISTÊNCIA: UMA REFLEXÃO CRÍTICA
}

\section{ARTIGO ORIGINAL}

CUNHA, Fernanda Lanzarini da ${ }^{1}$

FERNANDES, Rosa Maria Castilhos ${ }^{2}$

CUNHA, Fernanda Lanzarini da. FERNANDES, Rosa Maria Castilhos. Trabalho e resistência: Uma reflexão crítica. Revista Científica Multidisciplinar Núcleo do Conhecimento. Ano 05, Ed. 05, Vol. 11, pp. 74-110. Maio de 2020. ISSN: 2448-0959, Link de acesso: https://www.nucleodoconhecimento.com.br/saude/trabalho-eresistencia

\section{RESUMO}

Este texto procura congregar uma abordagem acerca dos fundamentos teóricos do trabalho, sua implicação na sociedade capitalista e seu impacto na vida da classe trabalhadora, visando realizar uma reflexão sobre trabalho e modo coletivo de resistência. Para isso, se discorre sobre os efeitos do modo contemporâneo de se relacionar com o trabalho, momento em que se verifica a acentuação da exploração dos trabalhadores e a supressão de seus direitos sociais. É a partir do debate acerca do modo de produção capitalista financeiro, em que se expande a degradação das relações e condições de trabalho, que se encontra espaço para argumentar sobre o modo de resistência coletivo. Nesse sentido, o texto demonstra o esforço em conectar a realidade com o contexto macro econômico e político do sistema de capital financeiro e as relações de trabalho. Salienta-se a relevância do resgate do sentido

${ }^{1}$ Especialização em Saúde do Trabalhador (UFRGS/2016). Graduação em Serviço Social (UFRGS/2014).

2 Doutorado em Serviço Social. Mestrado em Serviço Social. Especialização em Saúde Geral Comunitária. Graduação em Serviço Social. 
do trabalho através da organização coletiva dos trabalhadores, refletindo o potencial dos coletivos na promoção de saúde.

Palavras-chave: Trabalho, capitalismo, resistência, saúde do trabalhador.

\section{INTRODUÇÃO}

Este texto é resultado de reflexões realizadas no processo de aprendizado no curso de especialização em Saúde do Trabalhador na Universidade Federal do Rio Grande do Sul (UFRGS). É uma escrita que revisita conteúdos que subsidiam a apreensão crítica da realidade contemporânea do trabalho e sua dinâmica social em um contexto de ampliação da exploração e supressão dos direitos trabalhistas. Tal aprendizado e a consequente apreensão crítica da realidade favorecem compreender o mecanismo neoliberal onde o trabalho se desenvolve e que culmina na violação dos direitos dos trabalhadores em uma sociedade que se encontra em permanente disputa de projetos societários.

Para tanto, realizou-se uma revisão na literatura básica do curso de especialização que permite retomar conceitos teóricos centrais para analisar a atual configuração e centralidade do trabalho em um contexto de ampliação da extração de lucro em detrimento do bem-estar dos trabalhadores. É à luz da teoria social crítica que se pretende refletir a respeito das transformações do mundo do trabalho, permitindo compreender a dinâmica social de suas estruturas contemporâneas, favorecendo a análise e o pensamento crítico acerca do trabalho e da estratégia coletiva de resistência à lógica de acirramento da exploração do trabalhador.

Ao tratar das formas de resistência do trabalhador, objetiva-se pensar sobre estratégias de enfrentamento ao enxugamento dos direitos sociais da classe trabalhadora, pensando nos movimentos coletivos de luta a favor da saúde e proteção social dos trabalhadores. Assim, se discorre sobre as possibilidades de combate a precarização do trabalho, considerando a implicação da degradação das relações e condições de trabalho nesse processo. Neste artigo é dada ênfase ao sentido do 
trabalho e ao modo de resistência coletivo, o qual busca, além da reafirmação de direitos, resgatar a essência positiva do trabalho.

Para fins de organização este artigo é composto, além desta introdução, de três partes no desenvolvimento e das considerações ao final. A primeira parte é subdivida em três: a primeira trata das categorias explicativas do trabalho, apresentando subsídios teóricos para o entendimento do trabalho enquanto categoria central e fundante do ser social; na segunda se discorre acerca do modo de produção capitalista, de modo que se fala das principais características dessa fase e da relação do homem com o trabalho nesse contexto; na terceira é onde conceitualmente se trata do capitalismo financeiro e da sua explosão na contemporaneidade, reafirmando os interesses do capital em detrimento dos direitos e da saúde dos trabalhadores.

$\mathrm{Na}$ segunda parte do texto se discorre a respeito de algumas formas organizativas do trabalho, enfatizando como as transformações do mundo do trabalho se relacionam com o processo de saúde e doença dos trabalhadores. É neste momento que se elucida o desprazer ocasionado pelo trabalho em um contexto de perpetuação da retirada de direitos, do não reconhecimento e valorização, além da falta de sentido na construção da identidade do sujeito através do trabalho.

$\mathrm{Na}$ terceira parte se reflete a respeito do sentido do trabalho, elemento essencial no processo de saúde relacionado ao fazer laboral. A resistência coletiva dos trabalhadores frente às precárias condições de trabalho, incluindo relações fragilizadas e condições degradantes de trabalho, é trazida como condição essencial para o resgate do sentido do trabalho, expressando o potencial da organização política dos coletivos.

Por fim, as considerações expressam como a revisão bibliográfica e as problematizações trazidas se apresentam como condição essencial para se pensar a promoção da saúde do trabalhador. 


\section{CATEGORIAS EXPLICATIVAS DO TRABALHO: SUBSÍDIOS TEÓRICOS}

O trabalho, enquanto formador de valores de uso, enquanto trabalho útil é uma condição da existência do homem, independente de todas as formas de sociedade (MARX, 1975a).

Discorrer sobre a relação do homem com o trabalho no mundo contemporâneo implica em resgatar, mesmo que de modo muito sintético, as transformações dessa relação ao longo da história. Mas antes disso é importante lembrar que a categoria trabalho é uma das mais complexas da sociologia e possui várias significações, sendo a mais primordial delas o intercâmbio entre o homem e a natureza, tendo relação direta com a busca pela satisfação das necessidades vitais do ser humano. Segundo Alves (2007), este intercâmbio possui três dimensões: a dimensão consciente, que se refere à determinação reflexiva da categoria trabalho (consciência como prévia-ideação, como projeção); a dimensão técnica, mediada por objetos de trabalho e meios de produção; e a dimensão interativa-social que implica na relação do homem com outros homens - cooperação social.

Foi diante da relação do homem com a natureza, primeiramente e unicamente para fins de sobrevivência, que foi possível dar um salto ontológico que instaurou o ser social que "surge como pressuposto da atividade do trabalho humano também como produto da própria atividade do trabalho humano" (ALVES, 2007, p. 74). Assim, o homem, que somente se tornou homem através do trabalho, encontrou ao longo dos tempos muitas maneiras de se relacionar com a natureza e, nesse sentido, a evolução social tornou este intercâmbio complexo e diferenciado.

Para Netto e Braz (2010) o trabalho exige habilidades e conhecimentos que se adquirem por repetição e experimentação e que se transmite pelo aprendizado. Como somente o homem tem a capacidade de produzir se relacionando dessa forma com o trabalho, este se tornou hoje "uma atividade complexa, bastante socializada por uma sociedade humana cada vez mais social - no sentido de uma complexa divisão técnica do trabalho" (ALVES, 2007, p. 75). Nas sociedades pré-capitalistas houve múltiplas 
formas histórico-societais que caracterizaram o trabalho, mas é interesse, neste momento, tratar do mundo do trabalho sob a era do capitalismo.

É por meio do capitalismo que se constitui o mundo do trabalho, representando a forma social do trabalho mediante o trabalho abstrato que, por sua vez, é fonte de mais-valia (fonte de valor, de lucro), aparecendo como mercadoria na ótica do capital. Alves (2007) refere que

[...] os produtos/mercadorias existem em função da produção de maisvalia, isto é, do lucro, que é a forma contingente de aparição da maisvalia. As mercadorias que constituem a dinâmica social da sociedade burguesa existem não para satisfazer necessidades sociais, apesar de elas terem valor de uso, mas existem para servir a valorização do capitaldinheiro através da produção de mais-valia (p. 94).

Deste modo, surge a unicidade das atividades de luta pela existência, a forma social do trabalho abstrato, onde se envolvem as demais atividades prático-instrumentais em um processo sistêmico de acumulação de valor (ibid). A acumulação de valor é central na caracterização de um sistema capitalista, remetendo o trabalho como forma histórico-concreta de modo de produção social.

Toda forma de trabalho implica em um determinado modo de cooperação social e de apropriação do produto social da atividade deste trabalho, além de implicar em grau e modo de desenvolvimento das forças produtivas do trabalho social. Dessa forma, o trabalho expressa uma relação de ordem e obediência, ou seja, o trabalho na era capitalista pressupõe exploradores e explorados num período em que já se apresentavam as civilizações históricas com as classes sociais. Assim sendo, o trabalho tornou-se atributo de uma classe social determinada que obedece a ordens da classe dominante e advém dessa constatação o conceito de trabalho estranhado, onde as determinações de poder dominam os recursos naturais e apropriam-se dos meios de trabalho (ibid). 
No trabalho estranhado, o homem que produz através da sua força de trabalho (o trabalho vivo[3]) não se reconhece no produto final que foi construído em combinação com o meio (técnica) e com o objeto (matéria prima). Alves (2007) dialogou sobre o trabalho estranhado, o trabalho proletário e o trabalhador livre, no seguinte trecho:

O trabalho estranhado irá constituir o mundo moderno; não mais é claro como trabalho escravo, mas sim, como trabalho proletário, executado pelo "trabalhador livre". Entretanto, na sociedade capitalista, o trabalhador assalariado não é um pária, mas um citoyen integrado à sociabilidade mercantil vigente e reconhecido como sujeito de direitos ( $p$. 79).

Nesse contexto, compreende-se que o trabalho a partir da lógica capitalista se configura através de relações pautadas na exploração, pois se atribui a maisvalia/valor de troca às mercadorias e se concentra na propriedade privada os meios de produção. Essa relação está contida de determinação de poder político e de domínio dos recursos naturais por parte de pequenos grupos humanos que se distanciam do restante da sociedade.

Para Alves (2007) e Batista (2014), é com a constituição da sociedade burguesa que se aboliu o controle que os artesãos e camponeses tinham sobre o processo de trabalho, ou seja, o trabalho capitalista/assalariado extingue a possibilidade desse controle, o repassando exclusivamente para uso de alguns, que não os trabalhadores. Alves (2007) segue na argumentação a respeito do processo de cooptação do processo de trabalho:

[...] o desenvolvimento do processo de produção capitalista é, como observou Marx, o processo de alienação do homem dos elementos do processo de trabalho, alienação dos objetos de trabalho (matéria-prima), meios de trabalho (ferramentas) e inclusive do próprio trabalho vivo (o artífice e suas habilidades cognitivas). [...]. O surgimento do sistema de máquina tenderá a negar o processo de trabalho propriamente dito ( $p$. 81). 
Percebe-se, dessa forma, a importância da compreensão das origens do sistema capitalista, permitindo a conexão da atualidade com os elementos históricos explicativos e, nesse sentido, avalia-se importante relembrar as duas principais fases do capitalismo: o industrial e o financeiro. Resumidamente, foi no capitalismo industrial que se introduziram novas tecnologias e fontes de energia no processo produtivo. Nele, houve a transformação do modo de produção manual para o mecânico e a fabricação intensa de mercadorias, sendo estes os elementos estruturantes das relações sociais de produção e reprodução da vida dos homens (WÜNSCH, 2013; BATISTA, 2014).

Nessa linha, as relações sociais de produção envolvem contradições de classe (capital e trabalho) que se amplificam em contradições sociais (burguesia e proletariado) e políticas (governados e governantes). "Toda a sociedade torna-se o "lugar" da reprodução das relações sociais. Todo o espaço ocupado pelo capital transforma-se em "espaços de poder"' (LEFEBVRE, 1973, apud IAMAMOTO, 2011, p. 50).

A implantação de máquinas e a multiplicação das indústrias demandou a utilização de um número expressivo de trabalhadores, ampliando a classe operária e intensificando o êxodo rural pela necessidade do trabalho assalariado $e$ as consequentes transformações no modo de vida da época. Esse período foi marcado por importante transformação da organização do trabalho, incluindo a intensificação da produção, as péssimas condições de trabalho, os baixos salários, entre outras configurações que potencializavam a desigualdade social e deterioravam a saúde dos trabalhadores.

Após uma longa e expansiva onda de crescimento econômico, houve crises de natureza multicausal. A resposta neoliberal para a degradação das bases de acumulação do Estado se objetivou de três maneiras: 1) aprofundamento da globalização[4] e mundialização do capital caracterizado pela flexibilização dos mercados, deslocamento do capital financeiro e a articulação exterior com importação e exportação por menor preço; 2) reforma liberalizante do Estado, isto é, mediante a desregulamentação estatal que flexibiliza os direitos, caracterizado pela privatização dos serviços públicos e gestão direcionada pelos interesses neoliberais; 3) 
reestruturação produtiva que corresponde à matriz produtiva e força de trabalho, flexibilizando o processo de produção, refletindo o momento das novas tecnologias e vínculos empregatícios que modificam a dinâmica orgânica do mundo do trabalho.

A reestruturação produtiva, conforme Correia (1997) é um processo que

compatibiliza mudanças institucionais e organizacionais nas relações de produção e de trabalho, bem como a redefinição de papeis dos estados nacionais e das instituições financeiras, visando atender às necessidades e garantias de lucratividade (apud TITTONI, 2007, p. 89).

Sendo assim, esta reestruturação funciona como a expressão das transformações da sociedade no trabalho e essas pressupõem a ideia de globalização ou de mundialização da economia. O período de mundialização do capital apresenta a constituição de um novo regime de acumulação predominantemente financeiro, determinado pelas inovações tecnológicas de base microeletrônica e da organização e gestão do trabalho por rede informacional: máquinas de produção, controlativa, interativa e de reprodução social enquanto espaço de sociabilidade virtual apropriado pelo capital.

Sobre o capital financeiro, lamamoto (2011) explica que ele é originário da fusão entre o capital industrial e o bancário, remetendo ao processo de monopolização em que se concentra a atividade bancária, visto que 0

[...] sistema bancário mantém sua função de converter o capital monetário inativo em ativo, isto é, em capital que rende lucro ao reunir todo tipo de rendimento monetário a serviço da classe capitalista, inclusive os pequenos proprietários e camadas dos trabalhadores ( $p$. 101).

O período de acumulação de valor também é marcado pelo caráter flexível através de novas modalidades de contratação salarial e de novas formas de remuneração e flexibilização da jornada de trabalho. Conforme Tittoni (2007), as chamadas novas formas e gestão do trabalho priorizam 
[...] pacotes de formas de disciplinamento e de organização do trabalho [...]. Quanto às estratégias de subcontratação, têm demonstrado efeitos negativos no que concerne às "atividades de risco" para vida e saúde dos trabalhadores [...]. A não criação de vínculos formais entre os trabalhadores e os locais de trabalho dificulta, e muito, o acesso dos trabalhadores aos direitos sociais (p. 87).

Tal contexto é tão perceptível no atual mundo do trabalho, abrangendo tanto o setor privado como o público, em que se observa as transformações decorrentes da reestruturação capitalista que assolam a classe trabalhadora, atingindo, consequentemente, a saúde dos trabalhadores. Assim, a conjuntura política e econômica atual afeta as condições de vida da classe trabalhadora e implica na organização do trabalho de todas as categorias profissionais e todos os espaços de relações, ressaltando que o contexto histórico, político e econômico da sociedade capitalista é inerente às transformações produtivas no mundo do trabalho.

Netto e Braz (2010) ao tratarem do capitalismo contemporâneo, sintetizaram que sua configuração advém da dinâmica e protagonismo dos monopólios, constituindo assim a terceira fase do estágio imperialista. Ao complementar essa ideia, segundo os autores, as alterações econômicas ocorridas nas décadas de 60 e 70 do século XX, que determinaram o fim nos "anos dourados", levaram

[...] o capital monopolista a um conjunto articulado de respostas que transformou largamente a cena mundial: mudanças econômicas, sociais, políticas e culturais ocorreram e estão ocorrendo num ritmo extremamente veloz e seus impactos sobre Estados e nações mostramse surpreendentes [...] (p. 211).

Conforme visto até aqui, buscou-se resgatar algumas categorias centrais e explicativas do trabalho enquanto elemento fundante do ser social, assim como se relembrou, de forma muito breve, importantes momentos da sua evolução. Além disso, também foi possível retratar a centralidade da relação do homem com o trabalho e de como essa relação se transformou através de uma história marcada pela constituição 
do ser social e pela evolução do capital. Em continuidade, procura-se tratar a respeito da relação do homem com o trabalho mediante a inevitável imersão no mundo capitalista.

\subsection{HOMEM E TRABALHO NO MODO DE PRODUÇÃO CAPITALISTA}

Essa permanente incerteza que caracteriza o modo de produção capitalista é essencialmente advinda do fato de se tratar de uma sociedade baseada na propriedade privada dos meios de produção e no trabalho assalariado produtor de riquezas (WÜNSCH, 2013).

Ao se tratar da categoria trabalho percebem-se suas múltiplas determinações, dando ênfase a três dimensões. Em primeiro, a dimensão ontológica, aquela em que o trabalho é o intercâmbio entre o homem e a natureza, sendo este a base natural da constituição do ser social. Nessa linha,

o trabalho é, sempre, atividade coletiva: seu sujeito nunca é um sujeito isolado, mas sempre se insere num conjunto (maior ou menor, mais ou menos estruturado) e outros sujeitos [...]. Esse caráter coletivo da atividade do trabalho é, substantivamente, aquilo que se denomina social (NETTO, BRAZ, 2010, p. 34).

Em segundo, a dimensão histórico-concreta nas múltiplas formas societárias que surgiram com o desenvolvimento histórico, apreendida pelas formas de propriedade, relações sociais de produção e grau de desenvolvimento das forças produtivas sociais do trabalho (ALVES, 2007). Em terceiro, é a forma histórica do trabalho sob o modo de produção capitalista.

Autores como Alves (2007) e Wünsch (2013) manifestam em seus estudos que é no modo de produção capitalista que o trabalho encontra sua forma categorial mais desenvolvida, sendo este o seu maior grau de desenvolvimento sócio-histórico.

Apenas numa sociedade humana em que a categoria trabalho assume sua forma social mais desenvolvida e complexa, é que ele pode aparecer 
como trabalho em geral e não mais apenas em suas formas particulares (trabalho industrial, trabalho comercial ou ainda trabalho agrícola) (ALVES, 2007, p. 83).

Assim, é no modo de produção capitalista que se pode conceber o trabalho geral, que aparece como trabalho abstrato - forma desenvolvida de trabalho no modo capitalista. "O trabalho abstrato é a forma social do trabalho em geral e da atividade de produção de capital, perpassando as múltiplas atividades sociais particulares" (ibid, p. 83). Para o capitalismo o que importa é a geração de mais-valia contida nas mercadorias produzidas, pouco importando o tipo de trabalho concreto, muito embora nos dias atuais esse trabalho seja preponderantemente trabalho abstrato.

Portanto, o trabalho abstrato é a fonte do valor e elemento constitutivo do mundo do trabalho na modernidade do capital. $O$ trabalho abstrato se impõe como categoria social porque o sistema capitalista é o primeiro modo de produção da história da espécie homem baseado na lógica do mercado (ALVES, 2007). Além do mais, é com a modernidade do capital que a força de trabalho se torna mercadoria.

No reino do modo de produção capitalista é que a dinâmica social fica susceptível à dominação do capital, pois este possui o poder de marcar as mais variadas relações sociais, tornando tudo passível de compra e venda. Mais que isso, este modo de produção tem determinado a dinâmica social em nível mundial, considerando a predominância do capital financeiro globalizado. Isto é, o trabalho e a sociabilidade na era do capital são potencializados na mundialização financeira e conduz à potenciação da exploração do trabalho (IAMAMOTO, 2011).

Nesse sentido, o mundo do trabalho contemporâneo se apresenta aos trabalhadores como um campo de mil possibilidades para se trabalhar, onde tudo pode ser vendível, mediante criação da demanda. Para isso, primeiro se produz a mercadoria e depois, e consequentemente, demanda-se o seu consumo - criação da demanda de consumo. Diante de tal característica, típica do sistema de produção capitalista, constata-se que o homem se tornou, há muito tempo, um ser que não mais exerce atividades somente 
para o atendimento de suas necessidades naturais, implicando no desenvolvimento ilimitado de novas necessidades (NETTO; BRAZ, 2010).

Para Antunes (2001), a sociedade de consumo é produtora de desperdícios, que além de manipular o consumo do trabalhador, também manipula o seu tempo no trabalho, o seu tempo livre e não lhe permite viver uma vida repleta de sentido. Outra característica do sistema capitalista se relaciona ao fato de que os trabalhadores não se reconhecem no produto do trabalho e, tratando teoricamente da questão, o fetichismo da mercadoria e a reificação constituem a sociabilidade do capital, ou seja, é ocultado da mercadoria produzida o trabalho social realizado nesta produção; "toda mercadoria tende a ocultar sua origem como produto do trabalho social" (ALVES, 2007, p. 93).

Nesse caminho, o destino do homem diante do capitalismo tende a ser determinado pelos diversos tipos de mercado, como o do trabalho e o financeiro. O principal deles é o mercado de trabalho, tendo em vista que na sociedade do trabalho, "a identidade social é dada pela posição estrutural na divisão social do trabalho" (ibid, p. 85). Em resumo, o mercado dominante da sociabilidade burguesa, ou seja, o mercado de trabalho, determina as formas de subjetivação do homem moderno, apropriando-se da ação mobilizadora da subjetividade do sujeito pelo trabalho.

O regime do salariato, vigente mediante o trabalhador livre, isto é, o trabalhador assalariado, trouxe grandes modificações na estrutura do modo de produção. O pressuposto social do modo de trabalho histórico do salariato é o despossuimento, por parte dos trabalhadores, do controle dos meios de produção da vida material. Segundo Alves (2007), o salariato

[...] é base sócio-institucional da produção e reprodução social nas condições da produção ampliada de mercadorias, que pressupõe, como determinação essencial, a alienação/estranhamento dos produtores diretos dos meios de produção objetiva (e subjetiva) da vida material ( $p$. 90). 
Sendo assim, o sistema de produção impõe que o homem coloque a sua força de trabalho à venda, já que o sistema social do capital pressupõe a compra dessa força de trabalho em troca de salário, estando dessa forma, o homem capaz de sanar suas necessidades vitais.

As considerações acerca das formas do salariato nas sociedades burguesas oportunizam a apreensão dos modos de ser da classe trabalhadora assalariada. Nesse sentido, o mundo do trabalho dispõe de múltiplas inserções sociais dos modos de ser da classe trabalhadora, incluindo experiências de classe.

O modo de produção capitalista, no seu desenvolvimento histórico, ampliou e complexificou sua base produtiva e sua própria estrutura de classe. Outra classe social fundamental contida na classe dos trabalhadores assalariados é a burguesia. Na relação entre classe social de trabalhadores assalariados e classe social burguesa, surgem frações de classe vinculadas à divisão técnica e social do trabalho. Esse fenômeno atinge a classe dos trabalhadores assalariados - o proletariado - e se soma ao aparecimento de clivagens de gênero, étnicas, técnico-profissionais e de qualificação, conforme demonstrado por Alves (2007). O proletariado pressupõe a classe dos trabalhadores assalariados que vive da venda da sua força de trabalho e que se relacionam de forma subalterna com as relações sociais capitalistas de poder social estranhada.

Diante disso, o autor elucida o surgimento de um novo modo de ser, oriundo do sistema capitalista,

A classe dos trabalhadores assalariados e do proletariado enquanto complexo vivo do trabalho à mercê da exploração e espoliação do capital como sistema sócio-metabólico, incorporou, nos últimos trinta anos, com mais amplitude, outra importante clivagem que decorre das "novas formas de salariado" ou dos "modos de contratação salarial" (ALVES, 2007, p. 88). 
Percebe-se mediante o acirramento do sistema capitalista - que explora com mais veemência os trabalhadores que produzem de forma social e coletiva as riquezas, apropriadas por pequenos grupos burgueses detentores dos meios de produção - que este é capaz de inovar nas formas de exploração, agora com a roupagem de algo "inovador e moderno", mas que na realidade reforça a precarização do trabalho. Essa precarização possui um sentido de perda de direitos sociais e trabalhistas que decorreram da luta de classes e da correlação de forças políticas entre capital e trabalho, sendo, portanto, um processo com dimensão histórica (ALVES, 2007). Essa forma precária de trabalho é oriunda da crise estrutural do capital e desmonta as relações salariais e trabalhistas vigentes, buscando recompor a base da exploração da força de trabalho.

Ao falar do impacto sociológico da precarização do trabalho percebe-se que se torna mais difícil o desenvolvimento de consciência de classe necessária, tendo em vista que passam a coexistir com as formas precárias de contratação, pressões sociais e culturais em prol de práticas neocorporativas e de fragmentação vinculadas a interesses particularistas. Em outras palavras, o modo de ser do sistema capitalista enquanto trabalho precarizado, implode o núcleo de organização de base da classe assalariada, ou seja, as ações dos agentes do movimento sindical e político da classe do proletariado se fragilizam.

No campo político e ideológico o salariato precário significa a perda do referencial de classe, em que a visão dos interesses históricos de classe fica esmaecida. Portanto, a contingência do sistema do capital consequentemente fragmenta o proletariado e com isso esmorece sua unidade de classe. Mais do que nunca o trabalho social enquanto manifestação do trabalho abstrato adquiriu uma forma social tão estranhada, sendo tal estranhamento compreendido através da seguinte análise sobre a contradição do sistema do capital: "apesar da produção ser tão intensamente socializada, a apropriação é acerbadamente privada, inclusive através da apropriação dos fundos públicos" (ALVES, 2007, p. 89). Nisso, o estranhamento se dá pelo não reconhecimento dos trabalhadores entre si próprios em relação ao produto final que produziram. 
$\mathrm{Na}$ atualidade, o salariato precário advém de formas atípicas de trabalho que são formas sócio-históricas diferenciadas, como se percebe no caso de trabalhos não salariais, atividades autônomas, terceiro setor e estatutos salariais precarizados. Por isso, o regime de salariato não deixa de ser central na base sócio-institucional da sociedade burguesa.

$\mathrm{Na}$ medida do acirrado avanço de expropriação dos trabalhadores em relação aos meios de produção, a perda da autonomia desses sujeitos sociais é inevitável diante de tal agressividade do capital que os retira a possibilidade de capacidades e habilidades laborais. Neste caso, o salariato se institui como condição de produção e reprodução social mediante o trabalho assalariado. É na crise estrutural do trabalho, marcada pela reestruturação capitalista sob-hegemonia do neoliberalismo, em que os direitos trabalhistas são cada vez mais desmantelados, que a "civilização do salariato" se difunde. Isso decorre da precarização intensa das condições de contratação salarial do proletariado, sendo um momento de perda de direitos na busca da recomposição do acúmulo de valor (ALVES, 2007; WÜNSCH, 2013).

Batista (2014) explica que com o desenvolvimento da divisão técnica e social do trabalho as situações cotidianas tomam outros sentidos, pois deixam de ter uma única posição teleológica para dar espaço para duas ou mais posições. Nessa sociedade mais evoluída, o direito era parte constitutiva da superestrutura para regular a economia e o projeto societário da classe dominante. Então, depreende-se que em tempos contemporâneos, os mesmos direitos "criados" pelo sistema capitalista como elemento para a sua própria manutenção, vêm sendo corroídos pelo aprofundamento da exploração do capital sob a égide do capital financeiro.

É a partir dessa perspectiva e com a intenção de discorrer sobre a forma financeira do capital imersa no contexto neoliberal, que a seguir se trata, ainda que de forma sintética, sobre a dinâmica do capital financeiro e de que forma essa se associa com a explosão de agravos à saúde do trabalhador. 


\subsection{CAPITAL FINANCEIRO: ACENTUAÇÃO DA EXPLORAÇÃO}

Os neoliberais argumentam que as políticas sociais desestimulam o interesse pelo trabalho (WÜNSCH, 2013).

Ora! Será mesmo verdade que a classe-que-vive-do-trabalho foi quem levou o sistema capitalista a uma crise estrutural por estarem desinteressados pelo trabalho? Certamente ela não é nem mesmo conivente com os detentores dos meios de produção, cujo interesse é Ihes silenciar a cada dia enquanto exploram, de forma cada vez mais inovadora, sua força de trabalho.

A chamada "classe-que-vive-do-trabalho" é uma noção ampliada de classe trabalhadora, que incorpora tanto os trabalhadores produtivos, presentes nas indústrias, na agricultura e também no setor de serviços. Todos esses, privatizados pela lógica dominante do capital financeiro, como aqueles assalariados improdutivos que não geram mais-valia, mas que são imprescindíveis no processo de trabalho capitalista e vivenciam situações semelhantes daquelas experimentadas pelos trabalhadores produtivos. Como todo trabalho produtivo tende a ser assalariado, mas nem todo trabalhador assalariado é improdutivo, uma noção ampliada de classe trabalhadora deve articular essas duas dimensões (ANTUNES, 2010 apud ANTUNES; PRAUN, 2015, p. 408).

Após este preâmbulo conceitual sobre classe trabalhadora, cabe destacar o que ocorria em nível mundial no momento que antecedeu o triunfo do capital financeiro. Segundo Wünsch (2013), por conta da diminuição do crescimento econômico dos países desenvolvidos, incluindo a taxa de lucro, os proprietários do capital passaram a questionar o papel do Estado, assim defendendo a abertura da economia e promovendo a reestruturação da base produtiva. Isso significou o colapso de um Estado controlador da economia e promotor de políticas sociais mais amplas e solidificadas na área da proteção social e da garantia de direitos dos trabalhadores. Nesse momento, pairava em muitos países, principalmente nos desenvolvidos, porém não homogeneamente, um Estado de orientação keynesiana, sendo esta 
[...] uma teoria econômica consolidada [...] que consiste em uma organização econômica fundamentada na afirmação do Estado como agente indispensável de controle da economia, que deve operar como um regulador dos investimentos privados através do direcionamento dos seus próprios gastos enquanto indutor de investimentos, a fim de viabilizar um sistema de pleno emprego (NETTO; BRAZ, 2006 apud WÜNSCH, 2013, p. 64).

Diante desse contexto, se instalou o debate teórico entre os filiados a uma política econômica de orientação keynesiana e os de orientação neoliberal acerca da regulação das atividades econômicas para decidir se a mesma devia ser realizada por intervenção estatal ou pelo livre jogo das forças de mercado. Neste instante é oportuno lembrar que o pressuposto central do neoliberalismo é a dominação da economia através de forças autônomas do mercado global, com fundamento nas ideias de liberdade individual e valorização da propriedade privada e do mercado competitivo. Foi então, que os neoliberais tiveram vantagem, resultando na adoção, principalmente nos países desenvolvidos, de políticas econômicas que fragilizaram a luta da classe trabalhadora em prol de melhores condições contratuais, salarias, de trabalho e de vida.

A este propósito, pode-se afirmar que houve um impulso para a mundialização do capital, em razão de sua maior autonomia para "deslocamento diante da liberalização e da desregulamentação da economia facilitada pelas novas tecnologias e pelo limitado poder do Estado nesse aspecto" (CHESNAIS, 1996, apud WÜNSCH, 2013, p. 67). Assim, a mundialização do capital passou a se encontrar vinculada a um Estado ideologicamente neoliberal, sendo a forma política natural dos interesses do capital financeiro, na medida em que constitui a fração predominante do capital nas condições de crise estrutural de valorização (ALVES, 2007).

São os interesses do capital financeiro os mais beneficiados com a adoção das medidas de desproteção social, de desresponsabilização do Estado e de desregulamentação dos direitos, mecanismos operacionais do chamado Estado mínimo. Sendo assim, na concepção de Estado mínimo o seu papel é reduzido na 
regulamentação das relações comerciais e de produção, favorecendo o grande capital, não sendo prioridade 0 trato sobre 0 conjunto de reivindicação dos trabalhadores. É na predominância do capital financeiro, no qual a essência é a valorização do capital dinheiro, obtido com juros altos, que cresce exponencialmente os fundos mútuos de investimentos e de pensões, os grupos de seguros e os bancos multinacionais.

Dessa forma, o capital internacionalizado em amplo movimento de concentração e centralização da propriedade das empresas expande sua face financeira e especulativa, com irrestrita liberdade de operar sem regulamentações (IAMAMOTO, 2011; WÜNSCH, 2013). Desse modo, o que prevalece é a especulação que se organiza em torno dos mercados de câmbio e das taxas de juros, sendo através destes mecanismos que o capital financeiro opera sob a aprovação da política neoliberal vigente.

O capital financeiro, predominante através da mundialização do capital, se desenvolve via liberalização e desregulamentação da economia e das relações de trabalho, aliado ao uso de novas tecnologias da informação. Tais tecnologias são importantes ferramentas para que o controle da produção seja mais objetivo e o controle da jornada de trabalho seja aprimorado, havendo, assim, a intensificação da produção e a adoção de novas formas organizativas do trabalho em meio a ideias neoliberais predominantes.

É nesse contexto que a reestruturação produtiva constitui um componente fundamental das transformações societárias e do processo de recuperação do sistema do capital para a continuidade enquanto busca de reprodução ampliada do capital. Enfim, o incremento do novo complexo de reestruturação produtiva contribui para acentuar as contradições entre a enorme potencialidade produtiva para atender às necessidades básicas da humanidade e a exclusão de parcela significativa da população mundial desse processo (WÜNSCH, 2013, p. $69)$. 
Depreende-se, portanto, que além de significativa parcela da população não ter acesso aos bens produzidos, a hierarquia econômica e política se acentua entre os países em que se localizam os oligopólios das tecnologias avançadas e os países subdesenvolvidos (IAMAMOTO, 2011). Além do que, o capital estimula a propagação de novos modelos organizacionais, como no exemplo de subcontratação e terceirização do trabalho, resultando na precarização das relações e condições de trabalho.

A desregulamentação dos vínculos de trabalho e a financeirização do capital resultam na supressão constante dos direitos sociais dos trabalhadores, haja vista as inúmeras reformas da previdência, pública e privada, a título de exemplo. As variadas formas de contratação se colocam cada vez mais distantes da ideia de "segurança" no vínculo empregatício, pois os trabalhadores são contratados para trabalhos eventuais, temporários, por comissão, entre outros aspectos (WÜNSCH, 2013). A rotatividade de empregados é permanente, o que dificulta a organização coletiva dos trabalhadores em prol de seus direitos sociais e trabalhistas. A política de privatizações marginaliza os trabalhadores, favorecendo o grande capital financeiro internacional (BATISTA, 2014). Neste caso, os trabalhadores terceirizados e (re)terceirizados ficam sob risco iminente de total desproteção junto à muitas outras modalidades de contratação, não menos nocivas.

É nesse contexto que o capital produtivo, fundido em grande medida no capital financeiro, busca retomar o aumento do lucro ao introduzir mudanças significativamente maléficas para os trabalhadores e sua saúde no âmbito da organização sócio técnica da produção. Esse capital investe na diminuição de custos com força de trabalho e matérias primas, e, sobretudo intensifica os processos de trabalho. Tais medidas culminam na elevação da mais-valia e da velocidade de circulação do capital, centralizando-o em grupos internacionais, num cenário de desregulamentação e liberalização econômica, conjugando o principal fundamento do capital financeiro (WÜNSCH, 2013).

Antunes (2001) define bem a expansão do trabalho assalariado dizendo que se efetuou uma notória expansão do trabalho assalariado a partir da ampliação de 
assalariados no setor de serviços, também chamado de setor terciário. Além disso, se verificou uma significativa heterogeneização do trabalho expressa através da crescente incorporação de contingentes femininos no mundo do trabalho.

Percebe-se igualmente uma subproletarização intensificada, observada na expansão do trabalho parcial, temporário, precário, subcontratado e terceirizado, geralmente vinculados a uma economia informal, expressando as marcas de uma sociedade de capitalismo avançado. Houve, assim, uma redução do proletariado industrial e fabril, marcado pela época fordista[5], ao passo que há um aumento do subproletariado, marcado pela retirada de direitos, em que vigoram o emprego, o contrato e a remuneração precários no setor de serviços.

É principalmente a partir das inúmeras manifestações da desregulamentação das condições de trabalho que o capitalismo impõe sua supremacia à classe-que-vive-dotrabalho, explorando de forma alienante, como ocorre na contratação temporária, em que a demissão não tem custos para o empregador. Ao versar sobre trabalho e alienação, lamamoto (2011) elucida que

[...] na sociedade burguesa, quanto mais se desenvolve a produção capitalista, mais as relações sociais de produção se alienam dos próprios homens, confrontando-os como potências externas que os dominam. Essa inversão de sujeito e objeto, inerente ao capital como relação social, é expressão de uma história da autoalienação humana. Resulta da progressiva reificação das categorias econômicas, cujas origens se encontram na produção mercantil (p. 48).

Infere-se, dessa maneira, que este mecanismo, que aparece de modo disfarçado para o trabalhador, favorece a redução dos direitos trabalhistas e fragmenta a negociação coletiva entre empregadores e trabalhadores. É imperioso compreender de que modo a classe trabalhadora, inserida numa sociedade capitalista financeira, se relaciona com seu fazer laboral e com os demais âmbitos de sua vida, quer seja social, educacional, familiar, afetivo, etc. 
A seguir apresentam-se algumas características dos novos modos de organização do trabalho, objetivando refletir a respeito das particularidades das formas de precarização do trabalho e de como estas se relacionam com os processos de saúde e doença.

\section{A RELAÇÃO DO TRABALHO COM O PROCESSO DE SAÚdE E DOENÇA}

As experiências vivenciadas pelos trabalhadores ampliaram o universo individual e coletivo de reificação em seus diferentes níveis de sociabilidade, dificultando e impedindo-os de viverem e estruturarem uma vida plena de sentido (BATISTA, 2014, p. 209).

Como tem se percebido, cada vez mais o trabalho, principalmente aquele realizado sem sentido, ocasiona ausência de reconhecimento e realização advindos desta atividade tão primordial na vida do ser social. A falta de sentido no trabalho tem profundos impactos na saúde do trabalhador, estando relacionada à fragilização da saúde mental e física devido às dificuldades que encontram no mundo do trabalho em estruturarem uma vida laboral que Ihes traga satisfação, reconhecimento, sentido de utilidade e realização.

Por saúde do trabalhador se entende que ela expressa a relação entre o trabalho e a saúde nas suas determinações sócio históricas, políticas e econômicas, além da análise do trabalho coletivo e individual, sendo uma área de conhecimento interdisciplinar que envolve várias especialidades (MONTEIRO, 2013). Sendo assim, e de acordo com outros especialistas na área, reconhece-se que o trabalho possui centralidade na produção de saúde e doença (WERLANG, MENDES, 2013; MERLO, 2014).

É intenção aqui discorrer acerca de alguns elementos constitutivos do mundo do trabalho na era capitalista financeira que possuem características alienantes que, por sua vez, cooptam a relação do trabalhador com sua produção/trabalho fazendo com que não vejam sentido no seu cotidiano laboral. Tais características parecem estar 
dispostas no mundo do trabalho como naturais, cotidianas e normais, quando na verdade são formas de acirramento da extração de mais-valia, favorecendo o grande capital mediante a deterioração das relações de trabalho e dos direitos mínimos da classe trabalhadora.

De acordo com Merlo (2014), com a globalização neoliberal implantada a partir dos anos 1980, ocorre um processo de desregulamentação de todos os mercados e os investidores passam a aplicar seus métodos em nível planetário, obtendo lucros fenomenais, uma prática hoje banalizada. Nessa linha, há uma banalização da prática de desregulamentação generalizada das condições e relações de trabalho, levando os trabalhadores a crerem que o insucesso de uma vida laboral feliz é devido, unicamente, a ele próprio.

Um importante aspecto das mudanças organizacionais reforçado no mundo do trabalho contemporâneo são os chamados métodos "participativos" e em "equipe" que objetivam assegurar o envolvimento dos trabalhadores com a lógica do capital através do aumento da produtividade. Este elemento, constitutivo de um padrão organizacional, gera, consequentemente, uma distorção no pensamento do trabalhador, que se vê como indivíduo amplamente a serviço da empresa, tendo seus colegas como concorrentes, eliminando a unidade entre trabalhadores e gerando inúmeros agravos nas relações de trabalho.

A era do capitalismo financeiro requer trabalhadores com agilidade, criatividade, abertura para mudanças de curto prazo, que assumam riscos constantemente e que dependam cada vez menos de leis e procedimentos formais (SENNETT, 2006). Esse novo perfil de trabalhador, mais envolvido com a lógica do capital, disponibilizando sua energia física, mental e de saberes, institui uma competição em todas as dimensões, sendo inclusive estimulada entre os trabalhadores, dificultando a delimitação entre colega e concorrente, o que incide prejudicialmente na identidade de classe (classe trabalhadora).

Desse modo, a ênfase dada aos atributos pessoais, como nos exemplos de "empreendedor" e "colaborador do mês", responsabiliza individualmente o trabalhador 
pela sua inclusão ou exclusão no trabalho, refletindo a ofensiva ideológica na manipulação dos trabalhadores, ocasionando sérias manifestações patológicas no conjunto da classe trabalhadora diante de uma nova cultura do capital. Tais práticas incidem prejudicialmente e, principalmente, naqueles trabalhadores que, no ranking da concorrência entre colegas, já se encontram mais excluídos do ponto de vista da garantia do direito ao trabalho, incluindo relações hierarquizadas, de poder e de desigualdade salarial.

O capital persegue a conquista da hegemonia para efetuar a ampliação de sua acumulação através da superexploração dos trabalhadores utilizando-se de vários recursos, dentre eles, a extensão da duração diária do trabalho. Tal recurso é percebível diante da realização de trabalho à distância, por tarefa, por tele trabalho, assim como de outros sofisticados moldes, não havendo contabilização de horas de trabalho exercidas nesses termos. O trabalho frequentemente realizado no espaço particular retrata o potencial do capitalismo na invasão da vida privada dos trabalhadores, mais uma vez subordinando o âmbito social, familiar e de lazer à lógica da exploração do capital.

O capital enquanto relação social que tende ampliar a exploração do trabalho continuamente, necessita para isso, fragilizar a luta coletiva dos trabalhadores e efetuar inovações tecnológicas e métodos de gestão e organização da produção que garantam a superextração de capital. É exemplo de estratégias do capital para isso, a exigência de trabalhadores multifuncionais e polivalentes que estejam subordinados à lógica do capital, caracterizando a subordinação geral aos fins da lucratividade (IAMAMOTO, 2011).

A intensificação do ritmo de trabalho e a acentuação da subordinação do trabalhador ao processo mecânico de produção são reflexos do modo de produção capitalista financeiro que essencialmente busca o aumento da produção, impactando negativamente na saúde do trabalhador. A título de exemplificação a respeito do prejuízo à saúde do trabalhador pela intensificação do ritmo e do modo de trabalho, cita-se a incidência crescente de doenças osteomusculares por consequência de movimentos repetitivos, sem pausa e rodízio. Tal realidade ratifica a ausência de 
cuidado em saúde na maioria dos locais onde os processos de trabalho se desenvolvem, sendo o adoecimento profissional "um importante fator analítico sobre como o trabalho produz formas de exclusão social[6]" (TITTONI, 2007; MERLO, 2014).

Também são crescentes os casos de transtornos mentais e comportamentais relacionados ao trabalho, conforme apontado por Merlo (2014). De acordo com a previdência social, as concessões de auxilio doença acidentário neste âmbito cresceram 19,6\% em 2011 em relação a 2010. As doenças que mais compõem essas concessões são: "episódios depressivos, transtornos ansiosos, reações ao estresse grave e transtornos de adaptação, este último relacionado ao trabalho em escala, condições insalubres e recompensa insatisfatória" (ibid, p. 17).

Tais características do modo contemporâneo de organização do trabalho imerso na lógica neoliberal e no sistema capitalista financeiro refletem a agressão produzida pelo trabalho na saúde dos trabalhadores. Esta agressão também repercute na captura da subjetividade do trabalhador, impactando na forma de ser da classe trabalhadora, onde a finalidade do sistema capitalista é assegurar a subsunção real do trabalho ao capital (ALVES, 1999, apud WÜNSCH, 2013; MERLO, 2014) em detrimento das garantias, como saúde do trabalhador, previdência social, relações e contratos de trabalho seguros e solidificados.

Importante destacar que por subjetividade em relação ao trabalho, entende-se que são modos de sentir e vivenciar o labor como promotor de saúde, sentido e realização, portanto, tendo o trabalho um potente campo na produção da subjetividade (TITTONI, 2007). O viés da captura da subjetividade está ligado ao impedimento, mediante o trabalho alienante que destrói a capacidade do trabalhador de realizar-se nele, resultando em sofrimento no trabalho, com origens nas formas de disciplinamento e comportamentos através da implantação de normas e regras cada vez mais rígidas aliadas à supressão de direitos sociais e trabalhistas da classe trabalhadora.

As relações de terceirização não se limitam à produção e à comercialização, mas ampliam-se nas relações com outro capital a fim de apropriar-se de parte da maisvalia e de distanciar o trabalhador de seu potencial criador no trabalho. A terceirização 
da contratação da força de trabalho implica na fragilização dos direitos trabalhistas, estando o trabalhador intensamente subordinado à lógica do capital, pois neste tipo de contratação há pressão pela degradação das relações salariais, dos direitos trabalhistas, das relações e contratos de trabalho.

Portanto, se percebe o potencial do novo capital em efetuar deslocamentos no âmbito das relações tidas como "mais estáveis", já que esta lógica já impregna o âmbito público, como ocorre mediante a privatização dos serviços públicos engendrada pelo Estado. Este Estado, por força da classe dominante e da conjuntura política e econômica, pressionado pelo ideário neoliberal, tem se distanciado cada vez mais do seu papel garantidor e protetor dos direitos sociais para a população.

Outro elemento, ultimamente muito perceptível no mundo do trabalho, diz respeito ao emprego informal, advindo das relações precarizadas de trabalho que colocam em questionamento as suas formas de organização. Conforme Matosso (2010), dois em cada cinco trabalhadores brasileiros ativos dos grandes centros urbanos atuam na informalidade (apud WÜNSCH, 2013). De acordo com o autor, por conta do crescimento do trabalho informal e do desemprego, há uma redução dos investimentos governamentais e consequentemente um terreno fértil para a terceirização e a respectiva supressão de postos de trabalho.

Os elementos oriundos do acirramento da exploração da força de trabalho, em parte tratados neste artigo e que se encontram em grande medida banalizados, contribuem para a não construção, entre os trabalhadores, do processo de consciência de classe, esvaziando sua capacidade de organização política e de grupo com interesses em comum. Consequentemente, a organização de classe e a efetiva luta política no enfrentamento da retirada dos direitos sociais e públicos enquanto trabalhador fica fragilizada e com esmorecido impacto no contexto de ascensão neoliberal e de exploração mediante o triunfo do capital financeiro. Nesse contexto, a retração do movimento social e sindical dos trabalhadores é atribuída, em grande parte, pela repressão advinda dos atores que detém o poder político e econômico, impactando nas mobilizações em busca de melhores condições de trabalho e saúde pela classe trabalhadora. 
Não é difícil identificar e compreender a fragilização da capacidade dos trabalhadores em realizar movimentos coletivos em prol de melhores condições de trabalho. Encontram-se por todo lado, nas empresas de menor ou maior porte, e mesmo no meio público, trabalhadores muito afetados por baixos salários, por precárias e flexíveis formas de contratação, redução ou ausência de benefícios e direitos trabalhistas, subordinados à intensificação do trabalho e às formas de controle da jornada e do ritmo de trabalho. Nisto, impera a gestão sob pressão para o alcance de metas e resultados imediatos, ocasionando um sentimento de ausência de horizontes profissionais. A respeito disso, Raichelis (2013) aponta a presença desagregadora do produtivismo nas relações de trabalho,

responsável pela difusão da ideologia gerencialista como nova lógica de gestão do trabalho baseada em metas e produtividade, intensificação do trabalho, maior fiscalização e controle do trabalhador, estímulo a polivalência e competitividade, com amplo apoio nas tecnologias de informação e comunicação que esvaziam conteúdos reflexivos e criativos do trabalho (p. 401).

Para a autora, na base desse processo está o aumento da degradação do sentido do trabalho e da exploração deste, onde se verificam estratégias de redução do trabalho pago e ampliação do trabalho excedente, compondo junto aos vários outros aspectos, a origem do sofrimento do trabalhador assalariado. O sentido do trabalho é trazido por Costa (2013) como uma representação elaborada individualmente e/ou coletivamente, influenciada por diversas situações cotidianas compostas de elementos organizacionais, políticos, econômicos, culturais, sociais, individuais e coletivos.

As estratégias naturais da ofensiva capitalista na ampliação da sua acumulação de valor associadas às formas de terceirização do trabalho social, culminam na raiz do desgaste mental e do adoecimento. Desgaste e adoecimento provocados pelas relações de trabalho às quais os trabalhadores são submetidos, ou seja, estão permanentemente expostos às piores condições de trabalho, às situações mais penosas e humilhantes, aos trabalhos mais precarizados e mais sujeitos aos riscos, à 
corrosão mental e física, sendo os trabalhadores terceirizados o elo mais frágil na cadeia de exploração do trabalho (VICENTE, 2015).

Em grande medida, todas essas transformações que culminam em um "novo" modo de trabalho, se traduzem em regras e comportamentos legitimados como necessários para o desempenho da atividade laboral. Contudo, isso não passa do "aparente" que se coloca para a classe trabalhadora, significando no fundo transformações que produzem um modelo que pauta o comportamento e a conduta dos trabalhadores (TITTONI, 2007).

Não é possível, nem tem sido a pretensão desta escrita, realizar uma sinopse completa dos elementos constitutivos deste "novo" e amplo mundo do trabalho, justamente por se tratar de um tema extremamente complexo e por haver inúmeras interfaces da relação entre trabalhadores e detentores dos meios de produção. No entanto, tem sido possível discutir sobre algumas características que aprisionam os trabalhadores na sua vida laboral, aprisionamento que se estende para a vida familiar, social, afetiva e comunitária, acarretando em sofrimento que impede a emancipação humana através do exercício do trabalho.

Diante do cenário retratado até aqui, se faz necessário discorrer acerca de estratégia de resistência dos trabalhadores, também não sendo intensão a seguir, esgotar o assunto, tão pouco chegar à conclusão sobre como resistir aos modos nocivos do trabalho. Contudo, é intenção discutir, de modo muito breve, sobre a possibilidade de estratégia para resistir ao agravamento das condições de trabalho, enfatizando a relevância da mobilização coletiva no processo de saúde dos trabalhadores.

\section{SENTIDOS DO TRABALHO E RESISTÊNCIA COLETIVA}

Como visto, o trabalho ocupa centralidade na construção do bem-estar do trabalhador, sendo determinante na formação da identidade dos sujeitos e sua saúde mental, refletindo na própria representação social do trabalho. Essencialmente, o bem-estar no trabalho é compreendido, conforme Ferreira e Seidl (2009), por três eixos estruturantes: 
1) Satisfação no trabalho: estado emocional positivo ou de prazer, resultante de experiências de trabalho. 2) Envolvimento com o trabalho: grau em que o desempenho de uma pessoa no trabalho afeta a sua autoestima, representando vínculos positivos com o trabalho. 3) Comprometimento organizacional afetivo: estado no qual o indivíduo se identifica com a organização particular e seus objetivos, desejando manter-se filiado a ela com vista a realizar tais objetivos (apud ANTLOGA, AVELAR, 2013, p. 246).

Nessa linha, os efeitos "saudáveis" de um trabalho realizado com satisfação, entusiasmo e reconhecimento, são tidos como essenciais na promoção de saúde do trabalhador por meio de um clima de satisfação bem-estar no âmbito laboral. Contudo, em uma conjuntura de exploração do trabalhador que visa maximizar o lucro em detrimento da garantia de direitos e do seu bem-estar, essa relação saudável com o trabalho fica mais difícil de ser estabelecida, gerando a elevação dos processos de adoecimento aos trabalhadores expostos permanentemente à tal situação.

Mesmo diante de tal conjuntura, é preciso reconhecer que existem formas de resistência que se manifestam de variadas maneiras e, neste texto, resistência é tomada como força de contestação, de questionamento, de crítica frente à organização hierárquica e antidemocrática do trabalho e à supressão dos direitos sociais e trabalhistas. Nesse sentido, há inúmeras formas de resistir, mas neste momento é dada centralidade ao modo coletivo de resistir, ou seja, a resistência através do sujeito coletivo.

Como forma de reivindicação dos direitos da classe trabalhadora, o movimento dos trabalhadores tem sido historicamente coletivo, de modo que as mobilizações têm enfrentado uma correlação de forças cada vez mais desigual, sobressaindo-se a dos conservadores da ordem capitalista. Sobre isso, Barroco (2015) explica que o neoconservadorismo se apresenta como forma dominante de apoio conservador da ordem capitalista, "combatendo o Estado social e os direitos sociais, [...] reservando ao Estado a função coercitiva de reprimir violentamente todas as formas de contestação [...]" (p. 625). Por isso, a atuação coercitiva do Estado sobre as formas 
de reivindicação social é percebível constantemente no cenário brasileiro, havendo inúmeros exemplos, inclusive com ampla divulgação pelo aparato midiático, de combate à organização dos coletivos dos trabalhadores.

Ao se tratar de estratégias de defesa do trabalhador frente à degradação das condições e relações de trabalho, os trabalhadores tendem a adotar coletivamente tais estratégias, pois como refere Moraes (2013), as estratégias coletivas são mais eficazes porque contam com a adesão e a força de significativa parte do coletivo de trabalhadores. Infere-se, portanto, que estratégias defensivas coletivas são tomadas com o objetivo de ação transformadora de uma realidade repressora dos direitos sociais conquistados que a todo instante submete a singularidade do trabalhador aos ditames neoliberais. A respeito de estratégias defensivas, Dejours (2007), delineia que

[...] estratégias defensivas individuais somente têm resultado até certo momento [...] quando, então, perdem a eficácia na manutenção e sustentação da saúde [...] os trabalhadores devem procurar o desenvolvimento de estratégias de modo coletivo para, assim, ressignificar o sofrimento e amparar a saúde. $\mathrm{O}$ autor pondera que as estratégias defensivas individuais têm papel considerável na adaptação do indivíduo ao sofrimento, mas pouco alcance na violência social (apud COSTA, 2013, p. 378).

Além do mais, a luta coletiva carrega, mesmo que talvez implicitamente, a vontade de resgatar o significado emancipador do trabalho, aquele que gera prazer ao invés de desprazer. Como bem disseram Werlang e Mendes (2013), "faz-se necessário que o conteúdo do trabalho seja fonte de satisfação e que a "desalienação" seja elemento de transformação social" (p. 746). Depreende-se, portanto, que o trabalho não pode ser visto somente como uma atividade de produção e de cumprimento de normas, mas como algo transformador do mundo ao permitir que a criatividade e inventividade do homem se expressem.

Visando a luta coletiva em unidade é primordial que os trabalhadores se identifiquem enquanto classe e que o pensamento e as ações coletivas sejam privilegiados. 
Vislumbrando o sentimento de pertencimento ao coletivo, é preciso atuação dos próprios trabalhadores no sentido de prevenir a perda do sentimento de pertencimento, de utilidade e de reafirmação do bem-estar no trabalho. Lembra-se, nesse interim, que a dinâmica neoliberal e de exploração do trabalho está em constante movimento na tentativa de impedir o trabalhador de concretizar possibilidades de ação, pois o contexto neoliberal objetiva a estagnação do trabalhador frente aquilo que o traz sofrimento (WERLANG, MENDES, 2013).

O movimento coletivo dos trabalhadores é tomado para além do embate político ideológico na busca da garantia de direitos trabalhistas, sendo concebido também como forma de promoção à saúde do trabalhador, pois se trata de uma luta com caráter político e social que objetiva a qualidade de vida e o bem-estar para todos os integrantes da sociedade. Sobre isso, Czeresnia (2003) refere que as estratégias e intervenções relacionadas à saúde do trabalhador estão voltadas para mudanças nas condições de vida e trabalho (apud MONTEIRO, 2013). Ainda conforme a autora,

no contexto do trabalho, pode-se pensar que a promoção de saúde do trabalhador englobaria tanto o empoderamento do sujeito e do coletivo de trabalho, como mudanças nas formas de gestão do trabalho, abarcando instituições públicas e privadas (contexto micropolítico); e ainda questões mais amplas, envolvendo políticas de saúde do trabalhador (contexto macropolítico) (MONTEIRO, 2013, p. 294).

Nessa linha, compreende-se que o sentimento de pertencimento de classe, ou seja, a um grupo em comum, é gerador de condições favoráveis para a organização de coletivos que se identificam e se reconhecem, resultando em estratégias de transformação da realidade e no resgate do sentido do trabalho, isto é, daquilo que se expressa em contentamento no trabalho. O desenvolvimento de estratégias favoráveis, ainda que meio a um contexto desfavorável, aliado à organização político ideológica dos trabalhadores, resultam no enfrentamento à submissão generalizada dos sujeitos ao processo dominante de expansão do sistema do capital (FARIA, 2013). 
Sendo a organização de coletivos de trabalho entendida como forma de resistência dos trabalhadores frente aos ditames da ordem capitalista, é importante frisar que esta ação somente tem efeito quando aliada a outros mecanismos defensores dos trabalhadores. Sendo assim, também são reconhecidas como mecanismos de defesa da classe trabalhadora as organizações e políticas, internas e externas às instituições, de cuidado em saúde que refletem na reafirmação da própria política de saúde do trabalhador, implicando em espaços essenciais de fortalecimento do cuidado em saúde. Além destes mecanismos podem-se mencionar outras políticas sociais desenvolvidas com o intuito de garantir direitos sociais, como a política de seguridade social e a de educação, áreas articuladas com o direito ao trabalho e à saúde dos trabalhadores.

\section{CONSIDERAÇÕES FINAIS}

Este texto procurou compartilhar reflexões, advindas do processo de aprendizado no curso de especialização em saúde do trabalhador, acerca dos fundamentos teóricos do trabalho, sua implicação na sociedade capitalista e seu impacto da vida da classe trabalhadora, intentando versar sobre as categorias trabalho e resistência. Foi objetivo central nesta produção refletir criticamente sobre o impacto dos novos modos organizativos do trabalho na saúde do trabalhador, permitindo uma discussão que envolve a capacidade dos trabalhadores em ampliarem sua condição de sujeitos protagonistas, estando indiscutivelmente implicados no processo de acentuação da exploração do trabalho.

Tal objetivo abriu possibilidades de conectar o teórico com o real, repensando o sujeito trabalhador imerso no cenário de permanente retirada dos direitos trabalhistas e de restrição de possibilidades de satisfação no trabalho. E, acima de tudo, de repensar meios para a ocupação de espaços coletivos pelos trabalhadores como estratégia para resistir às constantes ameaças a seus direitos sociais, trabalhistas e, em especial, a sua saúde.

As considerações trazidas a respeito das configurações do capitalismo contemporâneo retratam a intensificação das pressões sobre os trabalhadores, dos 
temores, da insegurança, da submissão ao silêncio, da imobilização, da culpabilização e da individualização, verificando-se, dessa forma, a expansão do sofrimento social e a fragilização da saúde do conjunto da classe trabalhadora. Tais transformações acarretam, paralelamente à precarização das condições e relações de trabalho, a precarização da vida e da saúde em suas várias dimensões, deixando também frágil o estabelecimento de vínculo dos trabalhadores com ações emancipadoras e de desenvolvimento social no trabalho.

A nocividade da precariedade do trabalho dificulta a adoção de mecanismos de defesa individuais, pois os trabalhadores se veem impedidos de realizar ações emancipadoras, criadoras e realizadoras de felicidade no trabalho, pois a precarização tende a deixar os trabalhadores cada vez mais isolados. Nesse interim, a medida de resistência tomada neste artigo, ou seja, a estratégia de organização coletiva dos trabalhadores é discutida como condição importante, mas não única, de enfrentamento contra a retirada de direitos e a favor da ampliação da proteção e promoção da saúde do trabalhador, sendo considerado um mecanismo potente na transformação social do trabalho e no resgate do sentido deste. $O$ destaque dado ao modo de resistência coletivo advém da convicção de que somente é possível resistir coletivamente e dessa maneira engendrar transformações sociais e políticas.

Formas coletivas de resistência convergem em esforços unitários para a reelaboração do desenvolvimento de um trabalho que é acentuadamente ditado pelo modo de produção capitalista neoliberal, tentando resgatar a funcionalidade criadora, autônoma e realizadora do trabalho na vida e saúde dos trabalhadores. Nessa perspectiva, a ação política promovida pela organização coletiva é imprescindível no enfrentamento da violência no trabalho, expressando meio concreto para a superação de práticas violentas a desfavor dos trabalhadores. Contudo, a organização política da classe trabalhadora deve estar aliada a outras ações, visando impactar positivamente na relação entre trabalho e saúde, como por exemplo, o fortalecimento da própria política de saúde do trabalhador.

Enfrentar a violência no trabalho em seu próprio terreno, ou seja, no processo e nas relações de trabalho, é possível diante da organização coletiva dos sujeitos, assim 
como de outras formas, para fazer valer seus próprios objetivos, favorecendo assim o exercício de sua autonomia e reinventando seu modo de relacionar-se com o trabalho. Em suma, pensar os coletivos de trabalho expressa o próprio cuidado em saúde do trabalhador, além do mais, essa discussão assume posição contrária à derrota da reflexão crítica, objetivo do processo de expansão capitalista.

Esta reflexão pode expressar, diante do nefasto cenário de exploração do trabalhador e de supressão dos seus direitos sociais, a possibilidade de estabelecimento de um posicionamento crítico e propositivo acerca do contexto contemporâneo do trabalho. Além disso, pode também significar o esforço de reafirmação da relevância dos estudos a respeito da relação entre trabalho e saúde, tentando reunir um conjunto de ideias e aporte teórico que foram possíveis mediante a realização do curso de especialização em "Saúde do Trabalhador” na UFRGS (Universidade Federal do Rio Grande do Sul).

Ainda é preciso reconhecer que os fundamentos teóricos, o estudo conceitual na área, a reflexão e a própria proposição de ações são condição essencial para se pensar a promoção de saúde e a relação saudável do homem com o trabalho. Por fim, que a permanente indagação dos trabalhadores para consigo mesmos acarrete a reflexão crítica, no debate e na proposição de ações efetivas para a construção de modos de resistência que impliquem na prevenção e promoção da saúde, sendo o protagonismo dos trabalhadores central nesse movimento.

\section{REFERÊNCIAS}

ALVES, Giovanni. Dimensões da reestruturação produtiva: ensaios de sociologia do trabalho. 2aㅡ edição. Londrina: Praxis; Bauru: Canal 6, 2007.

ANTLOGA, Carla; AVELAR, Ricardo. Mal-estar no trabalho. In: Dicionário crítico de gestão e psicodinâmica do trabalho. Vieira, Fernando de Oliveira; Mendes, Ana Magnólia; Merlo, Álvaro Roberto Crespo (orgs). Biblioteca Juruá de psicodinâmica e clínica do trabalho. Curitiba: Juruá, 2013. 
ANTUNES, Ricardo. Adeus ao trabalho? Ensaio sobre as metamorfoses e a centralidade do mundo do trabalho. Biblioteca Latino-americana de Serviço Social. Cortez Editora. São Paulo, 2001.

ANTUNES, Ricardo; PRAUN, Luci. A sociedade dos adoecimentos no trabalho. In: Revista Serviço Social \& Sociedade, no 123. Trabalho, Saúde, Meio Ambiente. Cortez Editora. São Paulo, 2015.

BATISTA, Alfredo. Processos de trabalho: da manufatura à maquinaria moderna. In: Revista Serviço Social \& Sociedade, $\mathrm{n}^{0}$ 118. Trabalho precarizado. Cortez Editora. São Paulo, 2014.

BARROCO, Maria Lúcia S. Não passarão! Ofensiva neoconservadora e Serviço Social. In: Revista Serviço Social \& Sociedade, no 124. Conservadorismo, lutas sociais e Serviço Social. Cortez Editora. São Paulo, 2015.

COSTA, Sérgio Henrique Barroca. Sentido do trabalho. In: Dicionário crítico de gestão e psicodinâmica do trabalho. Vieira, Fernando de Oliveira; Mendes, Ana Magnólia; Merlo, Álvaro Roberto Crespo (orgs). Biblioteca Juruá de psicodinâmica e clínica do trabalho. Curitiba: Juruá, 2013.

FARIA, José Henrique de. Violência no trabalho. In: Dicionário crítico de gestão e psicodinâmica do trabalho. Vieira, Fernando de Oliveira; Mendes, Ana Magnólia; Merlo, Álvaro Roberto Crespo (orgs). Biblioteca Juruá de psicodinâmica e clínica do trabalho. Curitiba: Juruá, 2013.

IAMAMOTO, Marilda Villela. Serviço social em tempo de capital fetiche: capital financeiro, trabalho e questão social. 6ª edição, São Paulo, Cortez, 2011.

MARX, Karl. Manuscritos econômicos e filosóficos. Zahar, Rio de Janeiro, 1975.

MERLO, Álvaro Roberto Crespo. Sofrimento psíquico e atenção à saúde mental. In: MERLO, Álvaro Roberto Crespo; BOTEGGA, Carla Garcia; PEREZ, Karine Vanessa 
(Orgs.). Atenção à saúde mental do trabalhador: sofrimento e transtornos psíquicos relacionados ao trabalho. Porto Alegre: Evangraf, 2014.

MONTEIRO, Janine Kieling. Prevenção e promoção da saúde do trabalhador. In: Dicionário crítico de gestão e psicodinâmica do trabalho. Vieira, Fernando de Oliveira; Mendes, Ana Magnólia; Merlo, Álvaro Roberto Crespo (orgs). Biblioteca Juruá de psicodinâmica e clínica do trabalho. Curitiba: Juruá, 2013.

MORAES, Rosângela Dutra. Estratégias defensivas. In: Dicionário crítico de gestão e psicodinâmica do trabalho. Vieira, Fernando de Oliveira; Mendes, Ana Magnólia; Merlo, Álvaro Roberto Crespo (orgs). Biblioteca Juruá de psicodinâmica e clínica do trabalho. Curitiba: Juruá, 2013.

NETTO, José Paulo; BRAZ, Marcelo. Economia política: uma introdução crítica. $6^{\underline{a}}$ edição. São Paulo: Cortez, 2010. - (Biblioteca Básica de Serviço Social; v. 1).

RAICHELIS, Raquel. Proteção social e trabalho do assistente social: tendências e disputas na conjuntura de crise mundial. In: Revista Serviço Social \& Sociedade, no 116. Proteção Social. Cortez Editora. São Paulo. 2013.

SENNETT, Richard. A cultura do novo capitalismo. Rio de Janeiro: Record, 2006.

TITTONI, Jaqueline. Trabalho, poder e sujeição: trajetórias entre o emprego, o desemprego e os "novos" modos de trabalhar. Dom Quixote, Porto Alegre, 2007.

VICENTE, Damares. Desgaste mental de assistentes sociais. Um estudo na área da habitação. In: Revista Serviço Social \& Sociedade, № 123. Trabalho, Saúde, Meio Ambiente. Cortez Editora. São Paulo, 2015.

WERLANG, Rosangela; MENDES, Jussara Maria Rosa. Sofrimento social. In: Revista Serviço Social \& Sociedade, no 116. Proteção Social. Cortez Editora. São Paulo. 2013.

WÜNSCH, Paulo Roberto. Sindicalismo e reestruturação produtiva no Brasil: desafios da ação sindical dos metalúrgicos de Caxias do Sul/RS. Bauru: Canal 6, 2013. 


\section{APÊNDICE - REFERÊNCIAS DE NOTA DE RODAPÉ}

3. É importante salientar que, com o capitalismo, a força de trabalho, isto é, o trabalho vivo incorporado na produção de mercadorias, é também mercadoria. Eis um fato histórico da mais alta importância. "É a instituição social da força de trabalho como mercadoria que irá contribuir para que a forma-mercadoria se torne a célula-mater da sociabilidade" (ALVES, 2007, p. 81).

4. A noção ideológica de globalização, enquanto categoria mítica do capitalismo anuncia o mercado único, a difusão das tecnologias da comunicação através das quais as empresas poderiam produzir e vender em qualquer lugar possível e a um preço substancialmente idêntico (IAMAMOTO, 2011, p. 51).

5. Sobre o fordismo sugere-se ver Antunes (2001), onde o autor descreve que ele significa a produção em massa através de linha de montagem, estando presente o controle cronometrado do tempo e dos movimentos. Outra característica marcante do fordismo é o trabalho fragmentado, parcelado por funções, o que acarreta na separação entre elaboração e execução no processo de trabalho. A decadência do modelo de produção fordista, nada mais representou que a manifestação das crises permanentes do capitalismo.

6. São trazidos por Raichelis (2013), alguns exemplos de exclusão social devido à desproteção social e fragilidade no cuidado em saúde do trabalhador: mercado de trabalho que tende a escolher trabalhadores sem comprometimento físico ou psicossocial (comprometimentos muitas vezes oriundos de empregos anteriores); o convívio com a doença durante o período empregatício nem sempre resulta no estabelecimento do nexo causal devido os atendimentos em saúde não investirem na associação entre o relato do trabalhador e a natureza do trabalho exercido.

Enviado: Novembro, 2019.

Aprovado: Maio, 2020. 